\title{
SOME RADIUS OF CONVEXITY PROBLEMS FOR CERTAIN CLASSES OF ANALYTIC FUNCTIONS
}

\author{
KHALIDA I. NOOR AND HAILAH AL-MADIFER \\ Uatnematics Department \\ Jcience Coliege of Eiucation for Girls \\ Sitten Koaz, Fiyadin, Saudi Àrabia
}

(Received April 21, 1993)

ABSTRACT. In this paper we consicer some radius of convexity froblems for certain classes of analytic functions. Tnese classes, in general, are reiatej witn functions of bounded boundary rotation.

KEYWORDS AND PHARASES. Analytic functions, bounded boundary rotation, convex and close-to-convex functions. Univalent functions.

AMS(MOS) Subject Classification. Primary 30A32, Secondary 30A34.

\section{IIITRODUCTIOH.}

Let $V_{k}$ be tne class of functions of bounded boundary rotation. Paatero

[1] showed that a function $f$, analytic in $E=\{z:|z|<1\}, f(0)=0, f^{\prime}(0)=1$, $f^{\prime}(z) \neq 0$; is in $y_{k}$ if and only if, for $z=r e^{i \theta}$,

$$
\int_{0}^{2 \pi} \cdot \operatorname{Re} \frac{\left(z f^{\prime}(z)\right)^{\prime}}{f^{\prime}(z)} \mid \mathrm{d} \theta \leqslant k \pi
$$

It is geometricaliy obvious that $k \geqslant 2$ and $V_{2} \equiv C$, the class of univalent convex function.

A class $T_{k}$ of analytic functions related with the class $V_{k}$ nas been introduced and discussed in [2]. Let $f$ with $f(0)=0, f^{\prime}(0)=1$ be analytic in $E$. Then $f \varepsilon T_{k}, k \geqslant 2$, if there exists a function $g \varepsilon V_{k}$ such tnat, for z๕ت̈,

$$
\operatorname{Re} \frac{f^{\prime}(z)}{E^{\prime}(z)}>0
$$

It is clear that $T_{2} \equiv k$, the class of close-to-convex functions introduced by Kaplan [3].

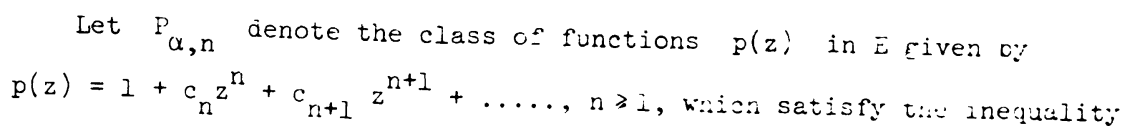




$$
\left|p(z)-\frac{1}{2 \alpha}\right|<\frac{1}{2 \alpha}, 0 \leqslant \alpha<1 .
$$

The class $P_{\alpha, n}$ has been introducez in [i]. If $\alpha=0$, the ciass $P_{\alpha, n}$ reduces to the classical class of functions with positive real part.

We shall need the following results in the next section.

Lemma 1.1[4]. Let $p \varepsilon P_{\alpha, n}$, tnen for $z \varepsilon E,|z|=r<1$

(i) $\frac{1-r^{n}}{1+c r^{n}} \leqslant i(z) \leqslant\left|p^{\prime}(z)\right| \leqslant \frac{1+r^{n}}{1-c r^{n}}$

(ii) $\left|\frac{p^{\prime}(z)}{p(z)}\right| \leqslant \frac{1+c i n r^{n-1}}{\left(++c r^{n}\right)\left(1-r^{n}\right)}$,

where $c=I-2 \varsigma$.

Lemma 1.2 [5]. If $I 1$ and $D$ are anaiytic in $E$ and $N(0)=D(0)=0$, and if $D$ maps $E$ onto many-sneeted region, which is starlike with respect to the orifin, then $\mathrm{K} \in \frac{\ddot{I}^{\prime}}{\mathrm{D}^{\prime}}>0 \Rightarrow \mathrm{Ke} \frac{\mathrm{I} i}{\mathrm{D}}>0$, zEE.

Lemma $1.3[6]$. Let $g \varepsilon V_{k}$. Then $G(z)=\frac{2}{z} \int_{0}^{2} g(t) d t$ is convex in the disc $|z|<\frac{1}{2}\left(k-\sqrt{\left.k^{2}-4\right)}\right.$.

\section{MAIN RESULTS}

In all of the theorems, s and $g$ will be analytic in $E, f^{\prime}(0)=1$, $f(0)=0$. The univalence will not be assumed unless explicitly stated. THEOREM 2.1. Let $g \in V_{k}$ and let $\frac{f^{\prime}(z)}{\varepsilon^{\prime}(z)} \varepsilon P_{\alpha, 1}$. Then $f$ maps $|z|<r$ onto a convex domain, where $r$ is the least positive root of

$$
c x^{2}-x^{2}(c x+c)-x(k+1)+1=0 .
$$

PROOF: Le: $\frac{f^{\prime}(z)}{E^{\prime}(z)}=p(z), p(z) \varepsilon: a, 1$.

Then

$$
\frac{\left(z f^{\prime}(z)\right)^{\prime}}{f^{\prime}(z)}=\frac{\left(z E^{\prime}(z)^{\prime}\right)}{E^{\prime}(z)}+\frac{z D^{\prime}(z)}{p(z)} \text {. }
$$

Hence

$$
\operatorname{Re} \frac{\left(z f^{\prime}(z)\right)^{\prime}}{f^{\prime}(z)} \geqslant \operatorname{Re} \frac{\left(z E^{\prime}(z)\right)^{\prime}}{E^{\prime}(z)}-\left|\frac{z D^{\prime}(z)}{p(z)}\right| \text {. }
$$

Now, it is known [7] that if $E \varepsilon V_{k}$, then

$$
\operatorname{Re} \frac{\left(z g^{\prime}(z)\right) \cdot}{E^{\prime}(z)} \geqslant \frac{r^{2}-k r+1}{1-r^{2}} \text {. }
$$




$$
\operatorname{Re} \frac{\left.\left(z f^{\prime}(z)\right)\right)}{f^{\prime}(z)} \geqslant \frac{c x^{2}-(z+2) c r^{2}-(k+1) r+1}{\left(1-r^{2}\right)(1+c r)}
$$

Thus $f$ is convex if the right nar.i side of (2.1) is positive.

Corollar $\because 2 . I$. Let $\alpha=0(c=1)$ waic: means $k \frac{f^{\prime}(z)}{E^{\prime}(z)}>0$. Then $f$ maps $|z|<r=\frac{(x+2)-\sqrt{\hat{k}+4 k}}{2}$ onto a convex domain. Tnis result was obtained in [2].

Corc 1 ar; 2.2. For $\alpha=\frac{1}{2}$, we thave $\left|\frac{f^{\prime}(z)}{\xi^{\prime}(z)}-1\right|<1$. Then $f$ is convex for $|z|<r=\frac{1}{r+1}$. For $k=4, v_{4}$ consists of univalent functions and $r=\frac{1}{5}$.

This resuit is known [4].

Corcllar; a.j. I: $x=u$, and $k=c$, inen $f$ maps $|z|<r=2-\sqrt{3}$ onto a convex domain. Inis result is wei-rnown [8].

REIiAiks 2.1. Let $\alpha=0$ and $k=4$. Tnen we obtain the known result $r=3-2 \sqrt{2}$ of Ratti [D].

THEORE 4 2.2. Let $\varepsilon \in T_{k}$ anj let $\frac{n^{\prime}(z)}{E^{\prime}(z)} \varepsilon P_{a, 1}$. Then $f$ maps $|z|<r$ onto a convex lumain where $r$ is the least positive root of the equation

$$
c x^{3}-(k+j c) x^{2}-(k+3) x+1=0 .
$$

PROOF: Let $\frac{f^{\prime}(z)}{g^{\prime}(z)}=p(z)$, where $p(z) \varepsilon P_{\alpha, I}, E \varepsilon T_{k}$.

Then

$$
\operatorname{Re} \frac{\left(z f^{\prime}(z)\right)^{\prime}}{f^{\prime}(z)} \geqslant \operatorname{Re} \frac{\left(z z^{\prime}(z)\right)^{\prime}}{\tilde{f}^{\prime}(z)}-\left|\frac{z p^{\prime}(z)}{p(z)}\right|
$$

For $g \in \mathrm{T}_{k}$, it is known [2] that

$$
\operatorname{Re} \frac{\left(z \xi^{\prime}(z)\right)^{\prime}}{\xi^{\prime}(z)} \geqslant \frac{r^{2}-(k+2) r+1}{1-r^{2}} \text {. }
$$

Using (2.4) and Lemma $1.1(i i)$, we obtain the result.

Corollary 2.4. Let $\alpha=\frac{1}{2}(c=0)$ and in tinis case $f$ maps $|z|<r=\frac{1}{k+3}$ onto a convex domain. The special case for $k=2$ is known [4].

Corollarv 2.5. For $\alpha=0$ and $k=2, \mathrm{~T}_{2} \equiv \mathrm{r}$ consists of close-to-convex univalent functions. Tnen the radius of convexity is $r=3-2 \sqrt{2}$. This result is known [9].

$\underline{\text { TilEOREI } 2.3}$. Let $\operatorname{Re} \frac{f^{\prime}(z)}{\varepsilon^{\prime}(z)}>0$ and $K \in \frac{g^{\prime}(z)}{S^{\prime}(z)}>0$, where $S$ belongs to the 
class $S^{*}$ of starlike functions. Tnen $f$ maps $|z|<r=4-\sqrt{15}$ onto a convex dorrain.

ROOF: We have

Inat is

$$
E^{\prime}(z)=S^{\prime}(z) h_{1}(z) h_{2}(z) \text {, where } \operatorname{Re} h_{1}(z)>0, \operatorname{Re} h_{2}(z)>0, \quad z \varepsilon E
$$

$$
\frac{z \cdot(z))^{\prime}}{z^{\prime}(z)}=\frac{\left(z z^{\prime}(z)\right)^{\prime}}{z^{\prime}(z)}+\frac{z n_{1}^{\prime}(z)}{h_{1}(z)}+\frac{z h_{2}^{\prime}(z)}{h_{2}(z)}
$$

irence

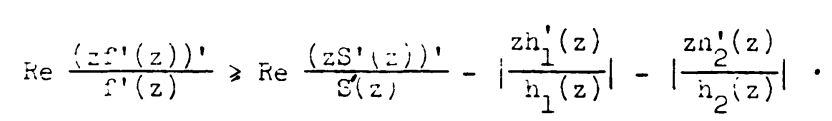

Now it is well rrown [8] tal for $3 \varepsilon S^{*}$,

$$
\operatorname{Re} \frac{\left(z z^{\prime}(z,)\right)}{i^{\prime}(z)} \geqslant \frac{1-4 r+r^{2}}{1-r^{2}}
$$

A sso, if he $r_{1}(z)>0$, then it is known [10] that

$$
\left|\frac{2 n^{\prime}(z)}{h(z)}\right| \leqslant \frac{a r}{1-r^{2}}
$$

Using (2.6) and (2.7), (2.5) yieldi

$$
\operatorname{Re} \frac{\left(z f^{\prime}(z)\right)^{\prime}}{f^{\prime}(z)} \geq \frac{1-8 r+r^{2}}{1-r^{2}}
$$

Hence $f$ is convex for $|z|<r=4-\sqrt{15}$.

THEOREM 2.4. Let $\operatorname{Re} \frac{f^{\prime}(z)}{g^{\prime}(z)}>0$ and $\operatorname{Re} \frac{g^{\prime}(z)}{S^{\prime}(z)}>0$ where $\operatorname{SE}^{\prime} \mathrm{T}_{\mathrm{k}}$.

Then $f$ maps $|z|<r=\frac{(k+6)-\sqrt{(k+6)^{2}-4}}{2}$ onto a convex domain.

The proof' follows on the same lines of 'Theorem 2.3 , by using (2.4).

Corollary 2.6. If $\mathrm{k}=2$, then $S \varepsilon \mathrm{T}_{2} \equiv K$. In this case $f$ inaps $|z|<\mathrm{r}=4-\sqrt{15}$ onto a convex domain.

THEOREM 2.5. Let $f_{\varepsilon V_{k}}$ and $f_{\alpha}(z)=\int_{0}^{z}\left(f^{\prime}(t)\right)^{\alpha} d t, 0 \leqslant u \leqslant l$. Then $f_{\alpha}$ maps $|z|<r$ onto a convex domain, where $r$ is the least positive root of

$$
(2 \alpha-1) x^{2}-\alpha k x+1=0 \text {. }
$$

PROOF: We have $f^{\prime}(z)=\left(f^{\prime}(z)\right)^{\alpha}, 0 \leqslant \alpha \leqslant 1$.

Thus

$$
\frac{\left(z f_{\alpha}^{\prime}(z)\right)^{\prime}}{f_{\alpha}^{\prime}(z)}=\alpha \frac{\left(z f^{\prime}(z)\right)^{\prime}}{f^{\prime}(z)}+(1-\alpha)
$$


Since $\mathrm{f}^{\mathrm{C}} \mathrm{V} \mathrm{V}_{\mathrm{k}}$, using (2.3), we have

$$
\operatorname{Re} \frac{\left(z f_{\alpha}^{\prime}(z)\right)^{\prime}}{f_{\alpha}^{\prime}(z)} \geqslant \alpha \frac{1-k r+r^{2}}{1-r^{2}}+(1-\alpha)=\frac{1-\alpha k r+(2 \alpha-1) r^{2}}{1-r^{2}}
$$

and this gives ui the requirel resuit.

THEOREM 2.6. Let $\mathrm{f}^{\prime} E \mathrm{~T}_{\mathrm{k}}$ and $\mathrm{f}_{\alpha}(z)=\int_{0}^{z}\left(\mathrm{f}^{\prime}(\mathrm{t})\right)^{x} \mathrm{dt}$. Then $\mathrm{f}_{\alpha}$ maps $|z|<\mathrm{r}$ onto a close-to-convex domain, where $r$ is tie least positive root of (2.8).

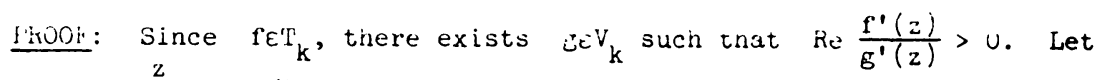
$g_{\alpha}(z)=\int_{0}^{z}\left[g^{\prime}(t)\right]^{\alpha} d t$. Then

$$
\left(f_{\alpha}^{\prime}(z) / g_{\alpha}^{\prime}(z)\right)=\left(f^{\prime}(z) / \dot{s}^{\prime}(z)\right)^{\alpha} \text {. }
$$

Using theorem 2.5, it follows that $\mathrm{f}_{\alpha}$ is close-to-convex for $|z|<r$, where $r$ is the least positive root of (2.8).

Corollary 2.7. Let $f \in T_{4}$, then $f_{x}$ is close-to-convex for $|z|<r$, where $r$ is the least positive root of

$$
(2 \alpha-1) x^{2}-4 \alpha x+1=0
$$

In this case, if $\alpha=\frac{1}{2}$, then $f_{\alpha}$ is close-to-close for $|z|<\frac{1}{2}$.

Corollary 2.8. Let $\mathrm{f} \varepsilon \mathrm{T}_{\mathrm{k}}$ and $\alpha=\frac{1}{2}$. Then $\mathrm{f}_{\alpha}$ is close-to-convex for $|z|<r=\frac{2}{k}$. For $k=2$, we have a result proved in [11].

Corollary 2.9. For $k=2, f_{\alpha} \varepsilon K$, see [11].

THEOREM 2.7. Let $f \varepsilon T_{k}$ and $F(z)=\frac{2}{2} \int_{0}^{z} f(t) d t$. Then $F$ maps $|z|<r=\frac{1}{2}\left(k-\sqrt{k^{2}-4}\right)$ onto a close-to-convex domain.

PROOF: Since ${ }^{f} \varepsilon T_{k}$, there exists a $g \varepsilon V_{k}$ such that $\operatorname{Re} \frac{f^{\prime}(z)}{g^{\prime}(z)}>0$. Let $G(z)=\frac{2}{z} \int_{0}^{z} g(t) d t$. We know, from Lemma 1.3 , that $G$ is convex for $|z|<r=\frac{k-\sqrt{k^{2}-4}}{2}$. Now

and

$$
\frac{F^{\prime}(z)}{G^{\prime}(z)}=\frac{\left(\frac{2}{z} \int_{0}^{z} f(t) d t\right)^{\prime}}{\left(\frac{2}{z} \int_{0}^{z} g(t) d t\right)^{\prime}}=\frac{N}{D}
$$

$$
\frac{N^{\prime}}{D^{\prime}}=\frac{f^{\prime}(z)}{g^{\prime}(z)}
$$


So $\operatorname{Re} \frac{N^{\prime}}{D^{\prime}}>0$. Applying Lemma 1.2 for $|z|<r=\frac{k-\sqrt{k^{2}-4}}{2}$

we have $\operatorname{Re} \frac{N}{D}>0$, which implies that $F$ is close-to-convex for $|z|<r=\frac{k-\sqrt{k^{2}-4}}{2}$.

Corollary 2.10. When $\mathrm{k}=2, \mathrm{f} \varepsilon \mathrm{T}_{2} \equiv \mathrm{K}$ and hence $\mathrm{F} \varepsilon \mathrm{K}$ for zEE. This result was obtained in [5] by Libera.

\section{REFERENCES}

1. PAATERO, $\vee$. Uber die rionforme Abbildung von Gebieten deren Rander von beschrankter Drenung Sind, Ann Acad. Sci. Fenn., Ser. A 33 (I033), $77 \mathrm{pp}$.

2. HOOR, K.I. On a Generalization of Close-to-Convexity, Int.J. Math. \& Viath. Sci. 6 $(1983), 327-334$.

3. KAPLAii, W. Close-to Convex Schlicht Functions, Michigan Math. J. $\underline{1}(1952): 169-185$.

4. SHAFFER, D.B. Radii of Starlikeness and Convexity for Special Classes of Analytic Functions, I. Nath. Analysis and Applications, 45(1974): 73-80.

5. LIBERA, R.J. Some Classes of Regular Univalent Functions, Proc. Amer. liath. Soc. 16(1965): 755-53.

6. KARUiAirARAil, $\because$. and PAD'if, $r$. Eunctions of Bounded Radius Rotation, Ir:dian $J$. Fure AFrl. :ati.., I2 $(5), 1951: 621-627$.

7. TAL:I, 0 . On certain Combinations for the Coefficients of Schlicht Functions, Ann. Acrì. Sai. Ser. AI(1952).

8. HAYMAI, W.K. Multivalent Functions, Cambridge, 1967.

9. RATII, I.S. The Radius of Convexity of Certain fnalytic Functions, indian J. Fure Appl. ilati. I $1(1970)$, 30-37.

10. MACGREGOR, T.H. The Radius of Univalence of Certain Analytic Functions, Proc. Amer. Math. Soc. $14(1963) ; 514-520$.

11. ROYSTER, W.C. On the Univalence of a Certain Integral, Michigan Math.J. 12, $(1965): 385-387$. 


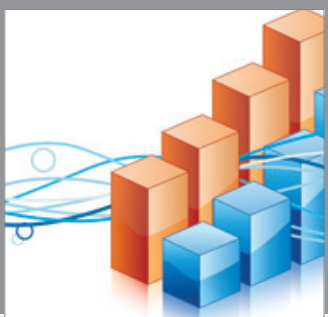

Advances in

Operations Research

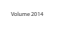

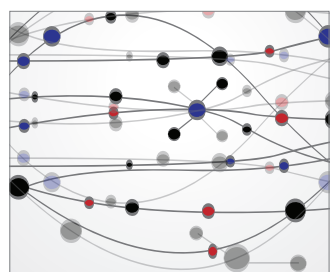

\section{The Scientific} World Journal
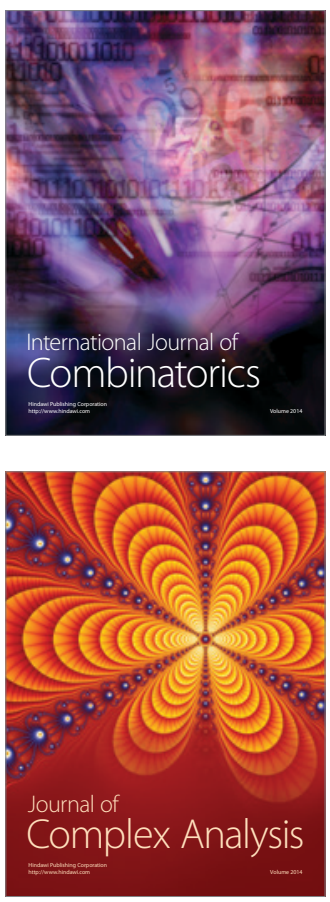

International Journal of

Mathematics and

Mathematical

Sciences
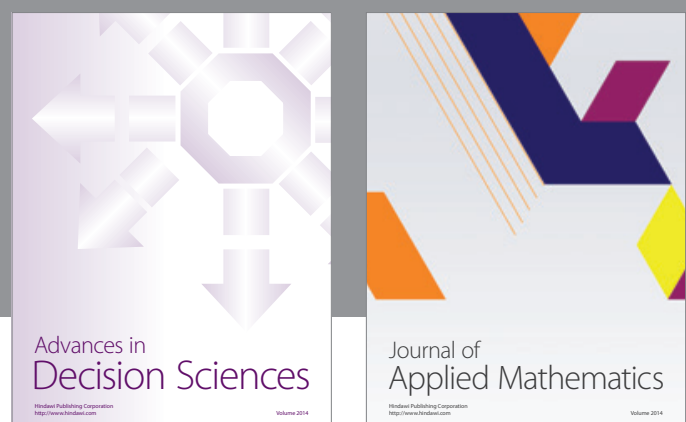

Journal of

Applied Mathematics
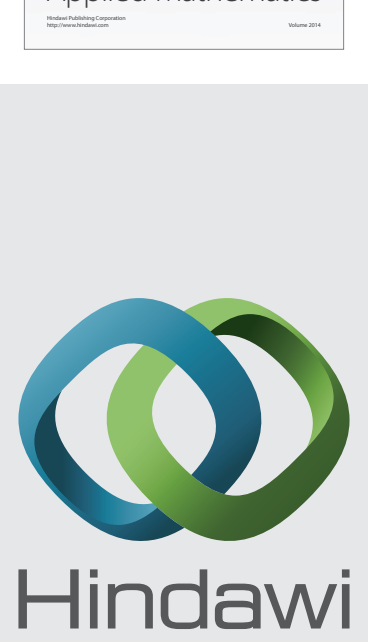

Submit your manuscripts at http://www.hindawi.com
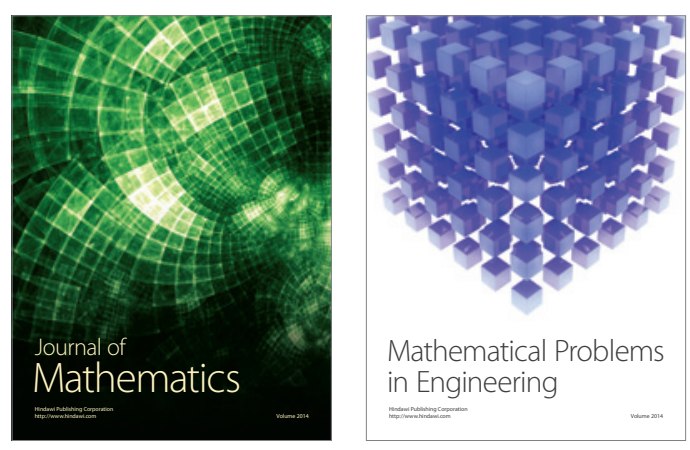

Mathematical Problems in Engineering
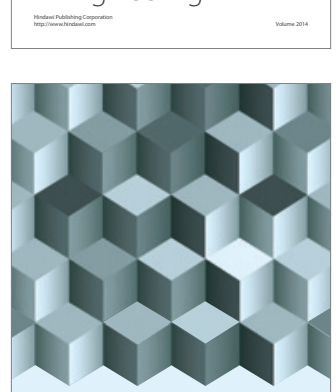

Journal of

Function Spaces
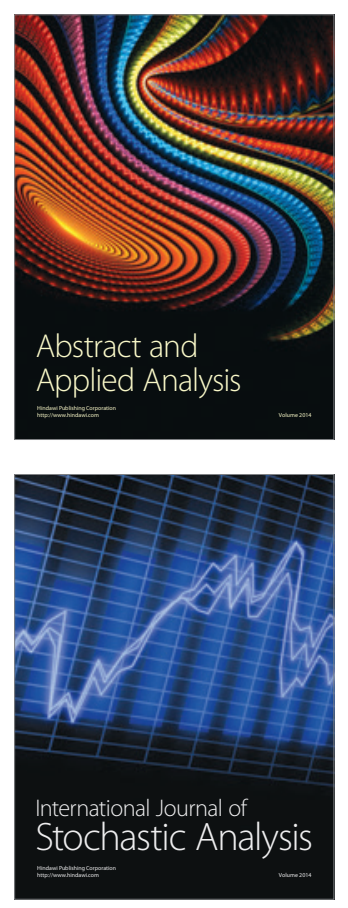

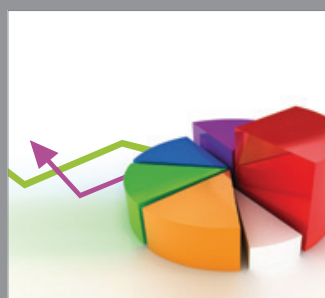

ournal of

Probability and Statistics

Promensencen
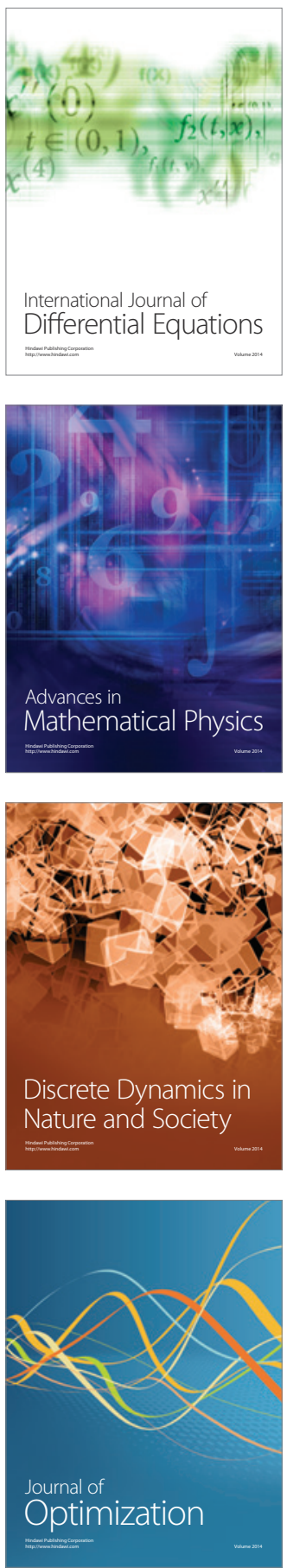